\title{
A enfermagem e o empreendedorismo: uma revisão narrativa sobre os desafios do
}

\section{enfermeiro empreendedor}

Nursing and entrepreneurship: a narrative review on the challenges of nursing entrepreneurs

Enfermería y emprendimiento: una revisión narrativa sobre los desafíos de los emprendedores de

enfermería

Recebido: 11/11/2021 | Revisado: 16/11/2021 | Aceito: 17/11/2021 | Publicado: 18/11/2021

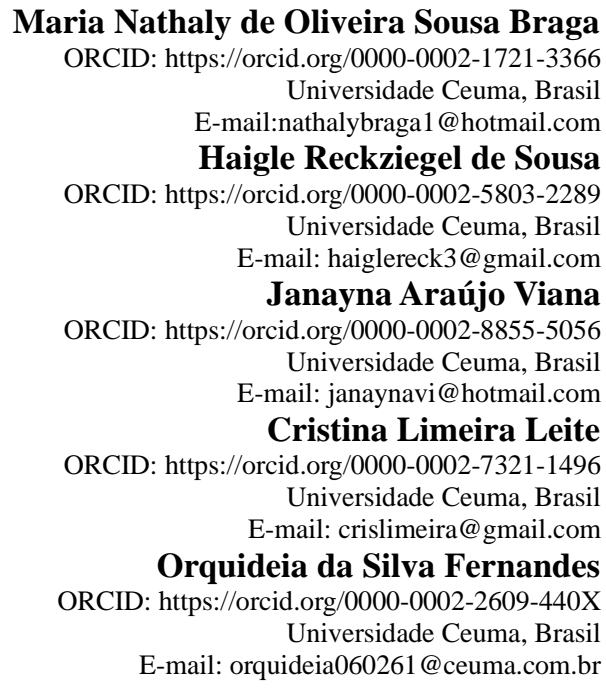

\begin{abstract}
Resumo
A enfermagem vem se tornando um setor cada vez mais propício ao empreendedorismo, com a extensão do serviço do profissional da enfermagem para além dos muros do ambiente hospitalar. Empreender vem sendo uma forma de conseguir um novo nicho econômico promissor para esse profissional. Este trabalho objetiva revisar o conteúdo produzido sobre o empreender na enfermagem, assim como, auxiliar pesquisas futuras na área. Trata-se de uma revisão narrativa, com abordagem qualitativa, onde foram feitas buscas em diversos periódicos de saúde, nacionais e internacionais publicados no período entre 2011 e 2021. O resultado do trabalho mostra que a enfermagem é uma profissão dinâmica, que exige resiliência, criatividade e coragem do profissional enfermeiro. O empreender na enfermagem não é o futuro da profissão, é o presente. Felizmente a dinâmica da profissão já possibilita ao profissional de enfermagem inovar, e como visto até aqui, inovar é um dos principais elementos do empreender. O que se busca, é uma melhor e mais completa formação acadêmica sobre a arte do empreender ainda na faculdade. Compreender os riscos e benefícios dessa ação, antes de concluir a graduação, pode definir o perfil profissional dos egressos do curso. Palavras-chave: Enfermagem; Empreendedorismo; Enfermeiro; Formação; Ensino.
\end{abstract}

\begin{abstract}
Nursing has become an increasingly favorable sector for entrepreneurship, with the extension of the professional nursing service beyond the walls of the hospital environment. Entrepreneurship has been a way of achieving a promising new economic niche for this professional. This work aims to review the content produced about undertaking nursing, as well as assisting future research in the area. This is a narrative review, with a qualitative approach, where searches were made in several health journals, national and international, published in the period between 2011 and 2021. The result of the work shows that nursing is a dynamic profession, which requires resilience, nurse's creativity and courage. Entrepreneurship in nursing is not the future of the profession, it is the present. Fortunately, the dynamics of the profession already enable nursing professionals to innovate, and as seen so far, innovating is one of the main elements of entrepreneurship. What is sought is a better and more complete academic training on the art of entrepreneurship while still in college. Understanding the risks and benefits of this action, before completing graduation, can define the professional profile of the graduates of the course.
\end{abstract}

Keywords: Nursing; Entrepreneurship; Nurse; Formation; Teaching. 


\section{Resumen}

La enfermería se ha convertido en un sector cada vez más propicio para el emprendimiento, con la extensión del servicio profesional de enfermería más allá de los muros del entorno hospitalario. El emprendimiento ha sido una forma de lograr un nuevo y prometedor nicho económico para este profesional. Este trabajo tiene como objetivo revisar el contenido producido sobre la realización de la enfermería, así como ayudar a futuras investigaciones en el área. Se trata de una revisión narrativa, con enfoque cualitativo, donde se realizaron búsquedas en varias revistas de salud, nacionales e internacionales, publicadas en el período comprendido entre 2011 y 2021. El resultado del trabajo muestra que la enfermería es una profesión dinámica, que requiere resiliencia, la creatividad y el coraje de la enfermera. El emprendimiento en enfermería no es el futuro de la profesión, es el presente. Afortunadamente, la dinámica de la profesión ya permite a los profesionales de enfermería innovar y, como se ha visto hasta ahora, la innovación es uno de los principales elementos del emprendimiento. Lo que se busca es una mejor y más completa formación académica sobre el arte del emprendimiento estando aún en la universidad. Comprender los riesgos y beneficios de esta acción, antes de finalizar la graduación, puede definir el perfil profesional de los egresados del curso.

Palabras clave: Enfermería; Emprendimiento; Enfermera; Adiestramiento; Enseñanza.

\section{Introdução}

Com os grandes avanços na área da saúde, a enfermagem vem se tornando um setor cada vez mais propício ao empreendedorismo, com a extensão do serviço do profissional da enfermagem para além dos muros do ambiente hospitalar, empreender vem sendo uma forma de conseguir um novo nicho econômico muito promissor para esse profissional, que muitas vezes, necessita cumprir uma jornada de trabalho excruciante e exaustiva para conseguir honorários suficientes para seu sustento. Hoje, o profissional de enfermagem, para manter uma boa moradia e proporcionar conforto a família, trabalha muito além das horas (Carvalho, 2004).

Para empreender é necessário um pouco mais do que vontade, é relevante que se tenha um preparo técnico para aventurar-se no mundo dos negócios, durante a graduação o enfermeiro passa por um complexo processo de formação profissional, através de estudos teóricos e estágios ele aprende a lidar com as mais diferentes adversidades no ambiente de trabalho, essa característica de inovar e solucionar problemas como falta de material, medicamentos e até mesmo de equipamentos tecnológicos necessários ao atendimento hospitalar, desenvolve nos enfermeiros um sentido aguçado e um perfil dinâmico e inovador favorável ao empreendedorismo na profissão. O empreendedorismo compreende a criação de algo novo, de valor, depois carece de devoção, comprometimento, de tempo e de esforço para fazer a empresa crescer; por último, necessita de ousadia, que se assumam riscos calculados, que se tomem decisões críticas e que não se desanime com as falhas e erros (Schmidt; Bohnenberger, 2009).

O curso de enfermagem na atualidade não se limita apenas a formar profissionais para atuar em hospitais. Alternativas que unem saúde e qualidade de vida, tem sido alvo de muitos profissionais da saúde e por isso se tornou uma área também de atuação para os bachareis de enfermagem. Para Waldon (2001) "Proporcionar saúde, vai além de evitar doenças é permitir meios e situações que prolongue e ampliem a qualidade de vida, que permita a autonomia e principalmente o bem-estar do indivíduo".

Autonomia do profissional enfermeiro pode ser alcançada através do empeendedorismo, já que esse seguimento comercial vislumbra o sucesso de uma negócio ou uma ideia através de um individuo ousado, criativo e capaz de criar soluções inteligentes para as adversidades que surgirem, é necessário além de preparo técnico, coragem para arriscar-se no empeendedorismo. Chiavenato (2007), define o empreendedor como um herói no universo dos negócios, pois este gera empregos através de inovações que favorecem o crescimento da economia e busca crescer, agregando espírito de liderança que contribuem para o fortalecimento e progresso da economia.

Ainda para Chiavenato (2004) o empreendedor é alguém com disposição para assumir riscos e benefícios do aproveitamento de oportunidades que outras pessoas veriam empecilho. Partindo dessa afirmação, chegamos à conclusão que o 
empreendedorismo busca inovações e oportunidade de negócios. Para que o negócio prospere precisa de mão de obra organizada, dedicada e comprometida, além de profissionais qualificados e dispostos a arriscar e tomar as rédeas do próprio negócio.

Diante do exposto surgiu o interesse de conhecer mais sobre os caminhos para o empreendedorismo da enfermagem, em vista que o atual cenário econômico brasileiro, a carreira de profissional autônomo apresenta grandes possibilidades de crescimento profissional, pessoal e econômico, além de ser uma alternativa para aqueles profissionais que não querem estar obrigatoriamente no ambiente hospitalar.

Esta pesquisa tem como objetivo fazer uma análise reflexiva sobre a importância da formação recebida pelos enfermeiros que decidem buscar a autonomia financeira e profissional através do empreendedorismo no campo da saúde, assim como discutir os desafios enfrentados por estes profissionais e também contribuir para pesquisas futuras, de enfermeiros que decidam seguir pelo caminho do empreendedorismo.

\section{Metodologia}

Este trabalho trata-se de uma revisão bibliográfica, na modalidade narrativa, com abordagem qualitativa. Este método viabiliza uma análise ampla da literatura disponível, subsidiando uma análise sobre a temática abordada, bem como um aprofundamento de como se dá o movimento empreendedor no nosso país ao que refere-se a atuação do enfermeiro como empreendedor.

Para Cordeiro (2007) revisão narrativa é considerada a revisão tradicional ou exploratória, onde não há a definição de critérios explícitos e a seleção dos artigos é feita de forma arbitrária, não seguindo uma sistemática, na qual o autor pode incluir documentos de acordo como seu viés, sendo assim, não há preocupação em esgotar as fontes de informação.

A revisão narrativa possibilita que o autor do estudo exponha suas ideias com mais liberdade, trazendo a tona o ponto de vista do pesquisador, proporcionando uma reflexão nova sobre temas abordados anteriormente na literatura. PAIVA (2008) descreve a pesquisa narrativa "como uma metodologia que consiste na coleta de histórias sobre determinado tema onde o investigador encontrara informações para entender determinado fenômeno”. Assim depois de analisar as obras selecionadas é possível fazer uma reflexão mais criteriosa sobre o tema.

Quanto a abordagem, este trabalho emprega métodos e técnicas típicos da abordagem qualitativa, que possui características próprias; hoje se constitui como um dos métodos mais utilizados para realização de pesquisas em áreas especificamente humanas (Neves, 1996).

Os artigos selecionados para a pesquisa são frutos de pesquisa realizada em periódicos disponíveis online. Foram utilizados como base de dados as seguintes revistas: Biblioteca Virtual em Saúde (BVS), Literatura Latino-Americana em Ciências de Saúde (LILACS), Base de Dados Bibliográficos Especializada na Área de Enfermagem e Scientific Eletronic Library Online (SCIELO).

No início da pesquisa utilizamos os seguintes descritores: empreendedorismo, enfermeiro, enfermagem e saúde, para abranger o maior número de fontes possíveis para as pesquisas. No total nestas bases de dados foram encontrados 39 artigos. Após uma busca mais detalhada foram eliminados os artigos duplicados. Chegou- se ao número de 31 artigos, com o objetivo de delimitar os artigos que atendesse melhor a nossa pesquisa, foram observados os resumos dos artigos e foram eliminados os que não abordavam, formação acadêmica empreendedora para o enfermeiro, e os artigos publicados há mais de 10 anos, foram selecionados assim 07 artigos que serviram de base para a elaboração do trabalho.

Os critérios de inclusão utilizados para a seleção da amostra foram: artigos publicados no período de 2011 a 2021 , com temas voltados para o perfil empreendedor do enfermeiro. Foram excluídos durante a busca: produções duplicadas, editoriais e cartas ao editor. Os critérios de inclusão adotados foram aplicados após leitura na íntegra dos textos selecionados, a 
Figura 1, seguinte, apresenta um fluxograma que, demostra o passo a passo tomado para chegar-se ao número de artigos estabelecidos para a revisão.

Figura 1. Trajetória artigos encontrados, 2021

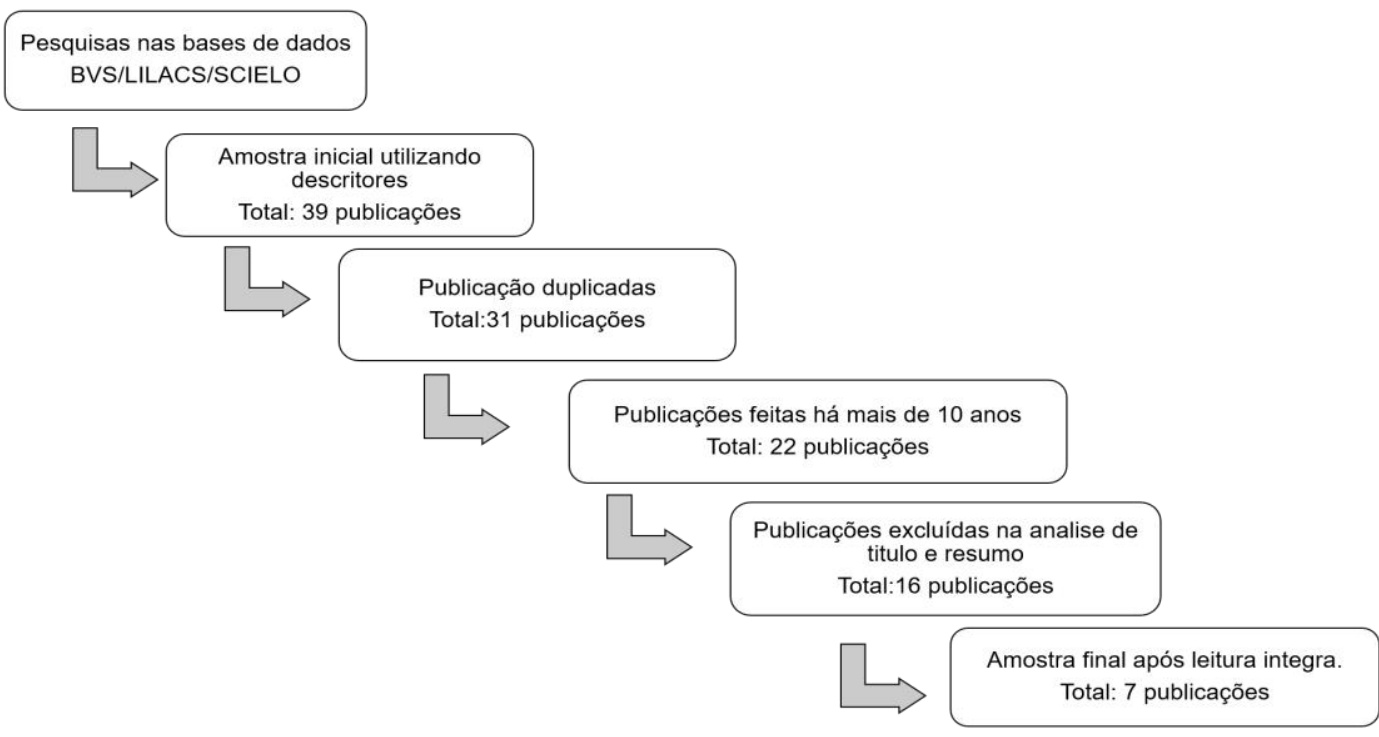

Fonte: Autores (2021).

\section{Resultados}

A amostra final desta revisão foi constituída por sete artigos científicos, selecionados pelos critérios de inclusão previamente estabelecidos. O Quadro 1 representa as especificações de cada um dos artigos, distribuídos, segundo título, autor, ano.

Quadro 1. Relação dos estudos selecionados para análise segundo ordem: título, autor, ano. Imperatriz-MA - 2021.

\begin{tabular}{|l|l|l|}
\hline \multicolumn{1}{|c|}{ TíTULO } & \multicolumn{1}{|c|}{ AUTOR } & ANO \\
\hline $\begin{array}{l}\text { Empreendedorismo na enfermagem: revisão } \\
\text { integrativa da literatura. }\end{array}$ & Copelli; Erdmann, Lorenzini. & 2019 \\
\hline $\begin{array}{l}\text { Empreendedorismo na enfermagem: comparação com } \\
\text { outras profissões da saúde. }\end{array}$ & Colichi. & 2018 \\
\hline $\begin{array}{l}\text { Práticas de Enfermagem Empreendedoras e } \\
\text { Autônomas. }\end{array}$ & Morais; Haddad; Rossaneis; Silva. & 2013 \\
\hline $\begin{array}{l}\text { O empreendedorismo como uma ferramenta para } \\
\text { atuação do enfermeiro. }\end{array}$ & Silva; Valente; Valente. & 2017 \\
\hline $\begin{array}{l}\text { Arte e Ciência do Cuidar: Alteridade Estabelecidos e } \\
\text { Outsiders na Autonomia do Enfermeiro como } \\
\text { Profissional Liberal. }\end{array}$ & $\begin{array}{l}\text { Silva; } \\
\text { Neto; Costa; Rodrigues; Alexandre. }\end{array}$ & 2019 \\
\hline $\begin{array}{l}\text { Empreendedorismo em Enfermagem: motivações e } \\
\text { possibilidades para o enfermeiro empreender. }\end{array}$ & Fonseca, GKL, Araújo, CL \& Olivindo, DDF. & 2020 \\
\hline \begin{tabular}{l} 
Empreendedorismo no campo da Saúde no Brasil. \\
\hline
\end{tabular} & Vieira; Rodrigues; Bottonni. & 2019 \\
\hline
\end{tabular}

Fonte: Autores (2021). 
No Quadro 2 é possível observar, uma síntese da descrição dos objetivos dos sete artigos escolhidos em conjunto com os principais resultados alcançados nas pesquisas destes. Na sequência apresentam-se os conceitos de empreendedorismo e empreendedorismo na enfermagem, alcançados após leitura dos estudos selecionados. Assim como a caracterização das áreas de atuação do Enfermeiro Empreendedor.

Quadro 2. Título, objetivo e resultado dos artigos selecionados. Imperatriz-MA - 2021.

\begin{tabular}{|c|c|c|}
\hline TÍTULO & OBJETIVO & RESULTADO \\
\hline $\begin{array}{lr}\text { Empreendedorismo } r & \text { na } \\
\text { enfermagem: } & \text { revisão } \\
\text { integrativa da literatura }\end{array}$ & $\begin{array}{l}\text { Evidenciar na literatura nacional e } \\
\text { internacional o conceito e as } \\
\text { tipologias de empreendedorismo na } \\
\text { Enfermagem. }\end{array}$ & $\begin{array}{l}\text { O conceito de empreendedorismo na Enfermagem está } \\
\text { relacionando a características pessoais e profissionais, como } \\
\text { autonomia, independência, flexibilidade, inovação, pró- } \\
\text { atividade, autoconfiança e responsabilidade. As tipologias } \\
\text { encontradas foram: empreendedorismo social, empresarial e } \\
\text { intraempreendedorismo. }\end{array}$ \\
\hline $\begin{array}{lc}\text { Empreendedorismo } & \text { em } \\
\text { Enfermagem: motivações } & \mathrm{e} \\
\text { possibilidades para } & \mathrm{o} \\
\text { enfermeiro empreender } & \end{array}$ & $\begin{array}{ll}\text { Analisar na literatura o campo de } \\
\text { atuação do enfermeiro no } \\
\text { empreendedorismo } & \text { em } \\
\text { Enfermagem. }\end{array}$ & $\begin{array}{l}\text { Perfil do enfermeiro empreendedor; Motivos e aspirações } \\
\text { que levam o enfermeiro ao Empreendedorismo de negócios; } \\
\text { Campo de atuação e variedade de negócios; Dificuldades e } \\
\text { limitações ao empreendedorismo de negócios na } \\
\begin{array}{l}\text { Enfermagem; Empreendedorismo na Formação } \\
\text { acadêmica. }\end{array}\end{array}$ \\
\hline $\begin{array}{l}\text { Empreendedorismo na } \\
\text { enfermagem: comparação com } \\
\text { outras profissões da saúde }\end{array}$ & $\begin{array}{l}\text { Identificar os aspectos que indicam } \\
\text { que o enfermeiro é empreendedor e } \\
\text { analisar as andências } \\
\text { empreendedoras dos enfermeiros. }\end{array}$ & $\begin{array}{l}\mathrm{O} \text { número de empresas de enfermagem abertas é } \\
\text { relativamente inferior àquele relacionado às profissões mais } \\
\text { jovens como fisioterapia, terapia ocupacional, psicologia, } \\
\text { nutrição e fonoaudiologia }\end{array}$ \\
\hline $\begin{array}{l}\text { O empreendedorismo como } \\
\text { uma ferramenta para atuação } \\
\text { do enfermeiro }\end{array}$ & $\begin{array}{l}\text { Caracterizar as empresas de } \\
\text { enfermagem e outras profissões da } \\
\text { saúde, comparando indicadores } \\
\text { relacionados ao empreendedorismo } \\
\text { entre essas categorias profissionais. }\end{array}$ & $\begin{array}{l}\text { A formação para o desenvolvimento de competências } \\
\text { técnicas e científicas precisa ser ampliada, pois, na } \\
\text { atualidade, o mundo do trabalho exige um novo } \\
\text { posicionamento dos profissionais enfermeiros. Uma postura } \\
\text { empreendedora; isto é, profissionais proativos perante as } \\
\text { mudanças mundiais das tecnologias, bem como do mercado } \\
\text { de trabalho. }\end{array}$ \\
\hline $\begin{array}{l}\text { Arte e Ciência do Cuidar: } \\
\text { Alteridade Estabelecidos e } \\
\text { Outsiders na Autonomia do } \\
\text { Enfermeiro como Profissional } \\
\text { Liberal }\end{array}$ & 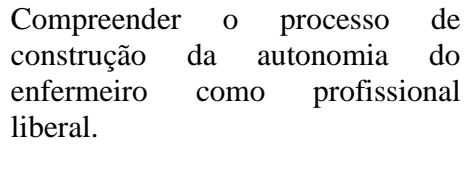 & $\begin{array}{l}\text { Foram identificados enfermeiros autônomos que, de forma } \\
\text { sistêmica, encontram-se como outsiders e que sofrem } \\
\text { estigmas pelos profissionais, comunidade e pelos próprios } \\
\text { outsiders. }\end{array}$ \\
\hline $\begin{array}{l}\text { Práticas de Enfermagem } \\
\text { Empreendedoras e Autônomas }\end{array}$ & $\begin{array}{llr}\text { Caracterizar } & \text { as práticas } & \text { de } \\
\text { enfermagem } & \text { empreendedoras } & \text { e } \\
\text { autônomas. } & & \end{array}$ & $\begin{array}{l}\text { O estudo evidencia que o enfermeiro possui campo de } \\
\text { atuação para o empreendedorismo, indo ao encontro da } \\
\text { afirmativa de que o profissional empreendedor tem a } \\
\text { possibilidade de disponibilizar serviços de enfermagem } \\
\text { envolvendo a prestação de cuidados, educação, pesquisa, } \\
\text { administração ou consultoria. }\end{array}$ \\
\hline $\begin{array}{l}\text { Empreendedorismo no campo } \\
\text { da Saúde no Brasil }\end{array}$ & $\begin{array}{l}\text { O objetivo de comparar a evolução } \\
\text { do empreendedorismo no Brasil } \\
\text { entre os anos de } 2002 \text { a } 2016 \text {. }\end{array}$ & $\begin{array}{l}\text { O empreendedorismo é progressivamente uma opção para a } \\
\text { nação brasileira em dois aspectos, colocar em prática a ideia } \\
\text { visionaria por conta própria ou para os afetados com a } \\
\text { presente crise econômica. }\end{array}$ \\
\hline
\end{tabular}

Fonte: Autores (2021).

\section{Discussão}

\subsection{Empreendedorismo}

Sabidamente o conceito de empreendedorismo pode assumir diferentes significados de acordo com o contexto cultural, social e econômico em que ele ocorre. Contudo existe uma unanimidade entre todos os estudiosos da área, que diz que para empreender é preciso inovar. Inovação é a palavra de regra nesse modelo de negócios, mas não significa somente inovar, no produto, empreender requer inovação em todos os níveis de um negócio. Outro tópico importante no empreender é dedicação, para que esse tipo de negócio prospere é necessário dedicação e esforço por parte de todos os envolvidos, Trigo 
(2005) evidência como característica do empreender a iniciativa de criar um negócio utilizando de forma criativa os recursos disponíveis, assumindo riscos e transformando o ambiente e o contexto que o cerca.

O fenômeno global do empreendedorismo, não possui uma receita de como alcançar o sucesso, mas para muito pesquisadores da área para empreender é necessário está atento a três características essenciais à quem deseja adentrar esse universo, a primeira característica está diretamente ligada ao comportamento do indivíduo que deve assumir um posicionamento de liderança, o segundo é ligado as habilidades técnicas que este indivíduo deve possuir, e o terceiro é relacionado ao comprometimento e a capacidade de assumir riscos. O empreendedorismo, como área de atuação inovadora na enfermagem, atua promovendo saúde a sociedade, através de seus consultórios, consultorias e auditorias. O empreendedorismo é significativo para movimentação e renovação da economia (Fonseca et al., 2020).

O mais importante nesse estudo é evidenciar que para empreender não basta apenas possuir um perfil empreendedor, é relevante que se tenha domínio do produto ou serviço oferecido, e que o indivíduo tenha compromisso e foco em desenvolver e inovar a cada dia, sempre visando atingir um público ainda maior, para se ter um negócio de sucesso. Guedes e Bolina (2020) afirmam que é necessário estudar a atuação desses profissionais para valorização e desmitificação de que o empreendedorismo é restrito ao ambiente empresarial.

\subsection{Empreendedorismo e Enfermagem}

Para Chiavenato (2004) o empreendedor é alguém com disposição para assumir riscos e benefícios do aproveitamento de oportunidades que outras pessoas veriam empecilho. Partindo dessa afirmação, chegamos à conclusão de que o empreendedorismo busca inovações e oportunidade de negócios, para que o negócio prospere precisa de mão de obra organizada, dedicada e comprometida, além de profissionais qualificados e dispostos a arriscar e tomar as rédeas do próprio negócio. Colichi; Lima (2018), apontam que o empreendedorismo vislumbra possibilidade de lucratividade e independência, autonomia, estar no comando, ser seu próprio chefe, possuir controle de carreira, ser bem-sucedido e busca pela satisfação profissional.

Várias áreas profissionais têm compreendido essa visão empreendedora, embora o empreendedorismo seja ainda forte nas áreas de economia e administração, as instituições de nível superior devem buscar pela formação de um profissional proativo e inovador, nessa concepção promovendo uma melhoria no perfil de seus profissionais (Couto Filho, 2014). Assim como em qualquer outra área para empreender na enfermagem é primordial conhecer o público que se quer atender, hoje é comum vermos, enfermeiros atuando em seus próprios negócios como: atendimentos domiciliares, consultorias de parto e amamentação, estética, cuidador de idosos, entre outras, cada uma dessas áreas de atuação vai exigir do profissional enfermeiro, além de conhecimento técnico, conhecimento sobre empreender.

Os empreendimentos abertos por profissionais da enfermagem refletem novos mercados de trabalho e sua análise pode ser interpretada como importante índice de empreendedorismo de negócios, assim como indicador da expansão da atuação desses profissionais no cenário atual. $\mathrm{Na}$ área de enfermagem, recentemente foi publicada a Resolução do Conselho Federal de enfermagem - COFEN nº 568/18, que regulamenta o funcionamento dos consultórios e clínicas de Enfermagem, valorizando o caráter empreendedor do enfermeiro ao reconhecer a personalidade jurídica desses serviços (Colichi; Lima, 2018).

Para empreender é necessário um pouco mais do que vontade, é relevante que se tenha um preparo técnico para aventurar-se no mundo dos negócios, durante a graduação o enfermeiro passa por um complexo processo de formação profissional, através de estudos teóricos e estágios ele aprende a lidar com as mais diferentes adversidades no ambiente de trabalho, essa característica de inovar e solucionar problemas como falta de material, medicamentos e até mesmo de equipamentos tecnológicos necessários ao atendimento hospitalar, desenvolve nos enfermeiros um sentido aguçado e um perfil 
dinâmico e inovador favorável ao empreendedorismo na profissão. Para Guedes; Bolina (2020), para exercer a enfermagem, é necessário trabalhar com a singularidades e limitações de cada indivíduo e grupos populacionais, deve haver habilidade e sensibilidade de realizar orientações direcionadas ao entendimento dos diversos públicos.

$\mathrm{Na}$ área da saúde principalmente na enfermagem o empreender não é uma novidade, como afirma Stein et al., (2014) "O empreendedorismo na saúde é a criação, gestão e busca cotidiana de alternativas para que o cliente tenha suas necessidades atendidas de forma singular e integral para tornar protagonista no processo de saúde". A busca por autonomia profissional e independência financeira, trouxe uma nova perspectiva para esse profissional, contudo ainda existem poucas bibliografias que falam sobre o tema, o que nos motiva ainda mais na realização dessa pesquisa.

\section{3 Áreas de atuação do Enfermeiro empreendedor}

Durante o processo de formação do enfermeiro, este indivíduo é educado para responder a ordens, e ser um bom empregado, todavia este tipo de educação que ensina ao enfermeiro ser subordinado está em conflito com a própria dinâmica da profissão que exige do profissional enfermeiro, pensamento rápido, criativo, dinâmico e inovador para intervir nas mais diversas situações do cotidiano. Tal conflito mostra a importância de sair da universidade preparado para atuar em um mercado de trabalho que vai além dos hospitais e postos de saúde. Copeli (2019) aponta que O empreendedorismo na Enfermagem permitiu a ampliação da visibilidade e consolidação da profissão como ciência, tecnologia e inovação, e complementa afirmando que está apesar de sua importância, é uma temática pouco discutida na literatura.

Atualmente existem várias áreas de atuação do enfermeiro, nos estudos analisados pode-se observar a ação do enfermeiro no campo: hospitalar; domiciliar; cuidados com a saúde e bem-estar; social; educacional; autônomo prestador de serviços e estético. Ampliar a discussão do empreendedorismo e das tipologias de empreendedorismo na enfermagem possibilita conhecer os campos que a profissão pode avançar (Copeli, 2019).

\section{Conclusão}

O empreender na enfermagem não é o futuro da profissão, é o presente. Felizmente a dinâmica da profissão já possibilita ao profissional de enfermagem inovar, e como visto até aqui, inovar é um dos principais elementos do empreender. O que se busca, é uma melhor e mais completa formação acadêmica sobre a arte do empreender ainda na faculdade. Compreender os riscos e benefícios dessa ação, antes de concluir a graduação, pode definir o perfil profissional dos egressos do curso.

Findada as leituras dos textos selecionados, existem muitos parênteses que precisam da atenção, os textos trazem muitos pontos de vista, mas todos os pesquisadores compartilham o pensamento de que é necessário que a grade curricular do curso de enfermagem precisa de mudanças que permitam que o empreendedorismo seja trabalhado de forma mais completa, incluindo assim na formação do profissional enfermeiro noções do empreender, e do mercado de trabalho em geral, pois com as mudanças econômicas que o país passa atualmente, todo e qualquer profissional precisa saber como se organizar economicamente.

Atualmente já existem cursos que abordam de maneira interdisciplinar ou transversalmente o empreender, mas diante das leituras feitas, e diante da escassez de trabalhos abordando a temática, percebe-se a necessidade de estudos discutindo a temática, e assim contribuir com a disseminação do assunto.

Sugere-se ainda, a inclusão da temática nos cursos de graduação, talvez uma disciplina exclusiva sobre empreender na grade curricular. Tendo em vista que, trabalhar o empreendedorismo ainda na graduação seria, descobrir se o estudante possui ou não um perfil empreendedor, pois como explanado anteriormente, empreender vai além de querer, é primordial ter um autoconhecimento do seu perfil profissional. 
Infelizmente no Brasil o empreendedorismo na enfermagem é usado amplamente não como uma vertente econômica, mas sim, como uma tentativa de valorização profissional e financeira, que não é possível atingir no ambiente hospitalar, é também uma fuga de uma rotina de trabalho exaustiva ao qual o enfermeiro se submete em busca de uma melhor rentabilidade.

\section{Referências}

Almeida, M. C. P. de. (1986). A formação do enfermeiro frente à reforma sanitária. Cadernos de Saúde Pública. Rio de Janeiro, 2(4).

Andrade, A. de C., Ben, L. W. Dal., \& Sanna, M. C. (2015). Empreendedorismo na Enfermagem: panorama das empresas no Estado de São Paulo. Universidade Federal de São Paulo, Escola de Enfermagem, Programa de PósGraduação em Ciências da Saúde. São Paulo-SP, Brasil. http://dx.doi.org/10.1590/0034-7167.2015680106p .

Brasil. (2014). Parecer 197/2014 de 26 de setembro de 2014. Parecer com posicionamento do Conselho Federal de Enfermagem sobre a legalidade da atuação do Enfermeiro e Técnicos de enfermagem na realização de procedimentos estéticos. Órgão Emissor: COFEN - Conselho Federal de Enfermagem.

Brasil. (2016). Resolução 529/2016 de 06 de novembro de 2016. Aprovar a normatização da atuação do Enfermeiro na área de Estética. Órgão emissor: COFEN - Conselho Federal de Enfermagem. http://www.cofen.gov.br/resolucao-cofen-no-0568-2018_60473.html.

Brasil. (2019). RESOLUÇÃO COFEN No 606/2019. Regulamenta o funcionamento dos consultorios e clinicas de enfermagem.Órgão Emissor: COFEN Conselho Federal de Enfermagem. http://www.cofen.gov.br/resolucao-cofen-no-0568-2018_60473.html .

Bottoni, A., Rodrigues, E., \& Vieira, P. R. (2019). Empreendedorismo no campo da saúde no brasil / Entrepreneurship in the field of health in brazil. Revista Brazilian Journal of Development (BJD). 5(7). DOI: https://doi.org/10.34117/bjdv5n7-045

Chiavenato, I. (2001). Teoria Geral da Administração, v.1. (6ª ed.), Elsevier.

Colichi, R. M. B., \& Lima, S. A. M.(2018). Empreendedorismo na enfermagem: comparação com outras profissões da saúde. Revista Eletrônica de Enfermagem, [s.1.], 20, 1-11.

Copelli, F. H. S., Erdmann, A. L., \& Santos, J. L. G. (2019). Empreendedorismo na Enfermagem: revisão integrativa da literatura. Rev Bras Enferm. 2019;72(Suppl 1):301-10

Frazão, D., (2019). Ana Néri Enfermeira brasileira. Ebiografia.com. https://www.ebiografia.com/ana_neri/

Fonseca, G. K. L., Araújo, C. L., \& Olivindo, D. D. F. (2020). Nursing entrepreneurship: motivations and possibilities for nursing entrepreneurs. Research, Society and Development, 9(7): 1-21, e597974442.

Guedes, dos S. J. L., \& Bolina, A. F. (2020). Empeendedorismo na enfermagem: uma necessidade para inovação no cuidado em saúde e visibilidade profissional. Rev Enferm. Foco.

Martins, C. R. N., \& Gomes, A. M. F. (2016). Debatedor: Mercado de Trabalho em Enfermagem: Aspectos Gerais. 2016.

Oguisso, T. (2007). Florence Nightingale. In: Trajetória histórica e legal da enfermagem. (2. ed.). Manole.

Rodrigues, R. M. (2001). Enfermagem compreendida como vocação e sua relação com as atitudes dos enfermeiros frente às condições de trabalho. Revista Latinoamericana de Enfermagem, Ribeirão Preto SP. https://doi.org/10.1590/S0104-11692001000600013

Sebrae.(2017). A profissionalização dos centros de estética: Estudo de mercado.

Vergara, S. C. (2000). Projetos e relatórios de pesquisa em administração. (3.ed.). Atlas.

Viana, R. A. P. P., Vargas, O. dee M. A., Carmagnani, S. M. I., Tanaka, L. H., Luz, K. R. da., \& Schmitt, P. H. (2014). Profile of an intensive care nurse in different regions of Brazil. Texto \& Contexto - Enfermagem, [s.1.], 23(1), 151-159, mar.

Waldow, V. R. (2001). Cuidado Humano: o resgate necessário. (3a ed.). Sagra Luzzatto.

Paiva, Vera Lúcia Menezes de Oliveira e (2008). A pesquisa narrativa: uma introdução. Revista Brasileira de Linguística Aplicada [online]. 8(2) Epub 16 Abr 2013. ISSN 1984-6398. https://doi.org/10.1590/S1984-63982008000200001.

Santos, C. V. dos. (2016). Desvendando os perfis empreendedores e seus reflexos no processo saúde-doença: revisão integrativa da literatura. / Clodoaldo Vieira dos Santos. - Cuité: CES.

Stein-Backers, Dirce et al. Significado da prática social do enfermeiro com e a partir do Sistema Único de Saúde brasileiro. Aquichan [online]. 2014, 14(4), 560-570. ISSN 1657-5997. https://doi.org/10.5294/aqui.2014.14.4.10.

Schmidt, S., \& Bohnenberger, M. C. (2009). Perfil empreendedor e desempenho organizacional. Rev. adm. contemp. [online]. 13 (3), 450-467. http://www.anpad.org.br/rac

Trigo, V. (2005). Doze meses de empreendedorismo. http://www.womenwinwin.com/documentos/image/informacao/doze-meses-de-empreendedorismoendash-prof-virginia-trigo-iscte-endashiul.pdf 